\title{
Dynamic behaviour analysis of an English-bond masonry prototype using a homogenized-based discrete FE model
}

\author{
Luís Carlos Silva ${ }^{1}$, Gabriele Milani², and Paulo B. Lourenço ${ }^{3}$
}

\begin{abstract}
Full Finite Element strategies (the so called micro- and macro- models) are still nowadays the most used ones for the study of large masonry structures. However, macro-modelling still lacks accuracy at a meso-scale in terms of damage localization. On the other hand, micro-models are rather computational demanding and require a cumbersome modelling stage. Thus, homogenization-based frameworks give considerable advantages. Moreover, the study of English bond masonry appears to be disregarded in comparison to the running bond one. On this behalf, a two-step procedure based on homogenization theory is herein presented for the dynamic study of English-bond masonry structures. The presented homogenization approach uses two models at a micro-scale: (i) a plane-stress FE discretization within the concepts of Kirchhoff-Love plate theory; and (ii) a three-dimensional micro-model accounting with the mortar joint discontinuity existent at the thickness direction. Bricks are meshed with elastic elements with linear interpolation and joints are reduced to interfaces which obey to the nonlinear behaviour described by the so-called combined cracking-shearing-crushing model. The procedure allows obtaining homogenized bending moment/torque curvature relationships to be used at a structural level within a FE discrete model implemented in a commercial code. The model relies in rigid quadrilateral elements interconnected by homogenized bending/torque nonlinear springs. The framework is used to study the dynamic behaviour of an English-bond masonry wall benchmark. A macroscopic strategy is also considered to enrich the study. The numerical results are compared with the experimental data and a good agreement has been found.
\end{abstract}

Keywords: Homogenization, Discrete FE, URM structure, English-bond masonry, Seismic assessment.

\section{Introduction}

The approach proposed in this paper belongs to the so-called multi-scale $\left(\mathrm{FE}^{2}\right)$ methods based on the homogenization theory. Homogenization is basically an averaging procedure performed at a micro-scale upon a Representative Volume Element (RVE). On the RVE, a Boundary Value Problem (BVP) is formulated allowing an estimation of the expected aver-age response to be used as constitutive relations at a macro-level. This framework has been used to investigate the behaviour of composites with different natures but is also useful for the study of masonry structures [1-6].

1 Ph.D. Candidate, Department of Civil Engineering, ISISE, University of Minho, Azurém, 4800-058 Guimarães, Portugal, luisilva.civil@gmail.com

${ }^{2}$ Associate Professor, Department of Architecture, Built environment and Construction engineering (A.B.C.), Technical University in Milan, Piazza Leonardo da Vinci 32, 20133 Milan, Italy, gabriele.milani@polimi.it

3 Full Professor, Dept. of Civil Engineering, ISISE, University of Minho, Azurém, 4800-058 Guimarães, Portugal. E-mail: pbl@civil.uminho.pt 
Homogenization theory seems the most efficient compromise between micro- and macro-modelling. The use of such approach is appealing because it allows to derive the macro-behaviour of masonry through the micro-scale characterization and thus considering its texture, components properties and expected micro-failure modes. In this way, the computational burden (in terms of CPU) is significantly reduced if compared with a fully micromechanical description of the material. Nevertheless, the classical $\mathrm{FE}^{2}$ approaches (in particular the full continuum-FE methods) are still a challenge in the non-linear range [7]. The advantages are especially obvious when linear elastic behaviour is assumed but obtaining a micro-scale solution at each load step for each Gauss point may turn the problem prohibitive from a computational point of view. These strategies still have a higher computational cost if compared with macro-modelling strategies.

If one intends to use homogenization strategies for the study of large or more complex structures, the development of techniques to speed-up the processing running times is critical. To accomplish the latter, the microscale unit-cell models are integrated within a micro- to macro- homogenized formulation, i.e. where the material constitutive information is transferred in one step from the micro- to the macro-scale. It can be very promising especially as several works demonstrate, with a good trade-off between accuracy and computational efficiency, for instance see [8-11].

The main aim of the present paper is to briefly present a two-step numerical framework, within two different homogenization procedures, to describe the dynamic behaviour of a masonry structure. Once the majority of the existing research on masonry deals with running-bond texture within a single-wythe walls case $[5,6,12,13]$, a complex three-dimensional English-bond masonry structure [14] is selected.

The ability of the procedure to reproduce the dynamic macro-behaviour of a complex three-dimensional masonry structure is assessed through available data from the English-bond mock-up tested in LNEC [14]. Additionally, the study aims to deepen the knowledge regarding both the effect of three-dimensional shear stresses and the presence of discontinuities or transversal joints on the masonry thickness.

\section{Numerical framework}

A two-step numerical procedure is introduced. The strategy makes use of a classical first-order homogenization scheme and is thus formed by: (i) the micro-scale problem solution; (ii) the micro-to-macro transition; and (iii) the solution of the macro-scale problem.

Two micro-scale homogenized models are used to characterize the behaviour of a masonry at a cell level: (1) a Kirchhoff-Love plate theory-based model (KP model); and (2) a three-dimensional micro-model homogeneous which accounts with the thickness discontinuity (3D DNS model).

To decrease the computational demand, material nonlinearity is assumed to be lumped on joints. This assumption seems to be adequate for strong block masonry structures. Both models were developed in DIANA and a fully automatic procedure was achieved by exploiting the software programming capabilities [15]. A multisurface plasticity model from Lourenço et. al. [16] (the so-called composite interface model) is considered for the interface elements used for the KP model. For the 3D DNS, the model from by Van Zijl [17] is adopted, 
which is an extension of the later to allow its use in a three-dimensional media. The plasticity models can reproduce well fracture, frictional slip and crushing along the interface elements.

The numerical models rely on a direct homogenization approach, which involves solving a micro-mechanical problem at a micro-scale and deriving average field variables. This information is then carried out to the macroscale to constitutively describe the behaviour of the structure. The definition of a proper RVE is essential, once it may be statistically representative of the body under study. Here, the RVE definition follows the recommendation by Anthoine [2].

The macro-structural behaviour is represented through a discrete element model, designated as Rigid Body Spring Mass (RBSM)., implemented in ABAQUS [18]. The methodology is briefly described in Figure 1 whereas the homogenized curves are transferred to a macro-scale. Two steps are developed to turn the macroinput independent from the macro-mesh i.e. the scaling and regularization of the homogenized quantities. For further details, the reader is referred to $[10,11,19]$.

\section{CASE STUDY}

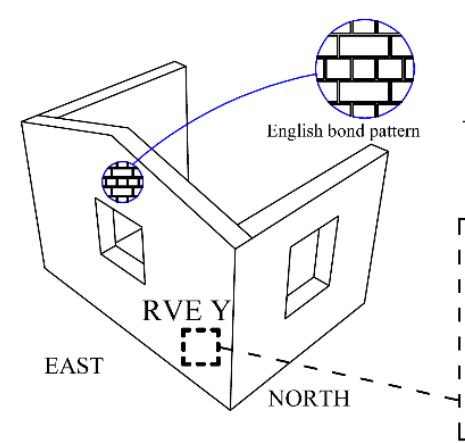

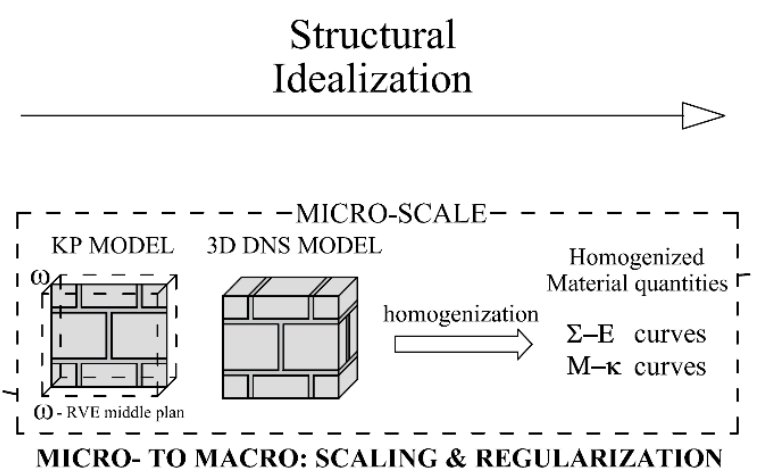

Structural dealization
MACRO-SCALE: RBSM model

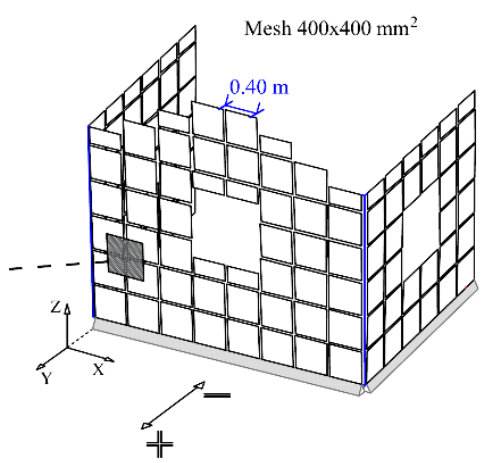

Figure 1. The case study and the methodology of the proposed two-step numerical procedure.

\section{Case study}

The selected case study outcomes from the experimental works performed at LNEC by Candeias et. al [14]. Candeias et al. tested an unreinforced brick masonry structure composed by three walls in a U-shaped plan arrangement. The main façade (East plan) presents a gable wall and is linked with two transversal walls which act as abutments (North and South plans). These are constructed with a clay brickwork in an English-bond arrangement of $235 \mathrm{~mm}$ of thickness. The clay brick units have nominal dimensions of $235 \times 115 \times 70 \mathrm{~mm}^{3}$ and are laid and bound together by mortar joints with a thickness ranging 15 to $18 \mathrm{~mm}$.

The brick mock-up was tested up to collapse in a shaking table under a unidirectional seismic loading. The seismic input is applied in a perpendicular direction (E-W) to the main façade and derives from the strong ground motion component registered after the February 21 of 2011 earthquake occurred in Christchurch, New Zealand. Although only quasi-static analyses are developed, the numerical damage is compared with the observed experimental failure mechanisms. 
Experimental investigations on the mechanical strength characterization of the studied English-bond masonry have been carried out and reported in [14]. A total of six masonry wallets were built but only three samples are defined as valid for the determination of the masonry stiffness and strength values. Briefly, it was observed that the specific mass is given by $1890 \mathrm{~kg} / \mathrm{m}^{3}$; the Young Modulus for the masonry brickwork is equal to $5170 \mathrm{MPa}$; the compressive strength is $24.8 \mathrm{MPa}$ and the tensile strength defined as $0.102 \mathrm{MPa}$. The latter data is summarized in Table 1.

Table 1. Material and mechanical information obtained via experimental works [14] and the assumed data for the homogenization step performed at a micro-scale [19].

\begin{tabular}{|c|c|c|c|c|c|c|c|c|}
\hline \multicolumn{9}{|c|}{ Experimental data } \\
\hline \multicolumn{2}{|c|}{$\begin{array}{c}\rho=1890 \mathrm{Kg} / \mathrm{m} 3 \\
(\mathrm{COV}=3 \%)\end{array}$} & \multicolumn{4}{|c|}{$\begin{array}{c}\text { Emasonry }=5170 \mathrm{MPa} \\
(\mathrm{COV}=29 \%)\end{array}$} & \multicolumn{2}{|c|}{$\begin{array}{c}\sigma c=24.8 \mathrm{MPa} \\
(\mathrm{COV}=14 \%)\end{array}$} & $\begin{array}{c}\sigma \mathrm{t}=0.105 \mathrm{MPa} \\
(\mathrm{COV}=19 \%)\end{array}$ \\
\hline \multicolumn{2}{|c|}{ Modal Identification: } & \multicolumn{4}{|c|}{ fmode-I $=10.69 \mathrm{~Hz}$} & fmode-II = & & fmode-III $=21.29 \mathrm{~Hz}$ \\
\hline \multicolumn{9}{|c|}{ Numerical data - Micro-Scale } \\
\hline \multicolumn{2}{|c|}{ Elastic Properties (Brickwork) } & \multicolumn{7}{|c|}{ Inelastic Properties (Mortar joints) } \\
\hline Ebrick & $v$ & $f_{t}$ & $f_{c}$ & $\mathrm{c}$ & $G_{f}^{I}$ & $G_{f}^{I I}$ & $G_{f}^{I V}$ & $\varphi$ \\
\hline $11000 \mathrm{~N} / \mathrm{mm}^{2}$ & $\begin{array}{c}0.20 \\
(-)\end{array}$ & $\begin{array}{c}0.105 \\
\mathrm{~N} / \mathrm{mm}^{2}\end{array}$ & $\begin{array}{c}2.48 \\
\mathrm{~N} / \mathrm{mm}^{2}\end{array}$ & $\begin{array}{c}0.20 \\
\mathrm{~N} / \mathrm{mm}^{2}\end{array}$ & $\begin{array}{l}0.012 \\
\mathrm{~N} / \mathrm{mm} \\
\end{array}$ & $\begin{array}{r}0.05 \\
\mathrm{~N} / \mathrm{mm} \\
\end{array}$ & $\begin{array}{c}3.97 \\
\mathrm{~N} / \mathrm{mm}\end{array}$ & $\begin{array}{c}30 \\
\text { degrees }\end{array}$ \\
\hline
\end{tabular}

\section{Macro-scale: the RBSM model}

The discrete FE-method based procedure stems from the model presented by the authors in [10,11]. To represent both in- and out-of-plane deformation modes, the latter strategy has been slightly changed to integrate the inplane model. The RBSM model, whose theoretical background is inspired in the works of Kawai [20], is composed by the assemblage of discrete quadrilateral rigid plate elements interconnected, at its interfaces, through a set of rigid and deformable FE truss-beams, see Figure 2. The truss-beam elements govern both the deformation and damage of the structure, by being able to mimic the presence of the in- and out-of-plane failure modes considered in Figure 1 and within a decoupled characterization. These can append the material information of the micro-scale homogenized step and thus represent the masonry texture via an equivalent continuum media, by accounting with its orthotropy and full softening behaviour description.

Regarding the representation of the inertial forces, which highly affect the dynamic behaviour of a structure, the mass of the system shall be introduced. The mass of the system is embodied by the quadrilateral rigid plates using an equivalent material density which, following a linear displacement interpolation assumption, allows to achieve a consisted mass matrix. In this scope, the discrete element approach has been implemented into the commercial finite element software ABAQUS [18]. There are obvious advantages by developing such practicaloriented strategy at a structural scale. In fact, the software is robust and stable when in the presence of material softening (more evident in the nonlinear static analysis), once built-in features are at disposal, as the line search algorithm and the arc-length procedure. It is also adapted to possibly the execution of the macro-level response calculation within parallel computing. This has a special interest to speed-up the processing times for dynamic or large-scale problems. The concrete damage plasticity (hereafter, CDP) mode, available in ABAQUS [18] is selected given the better representation of the inelastic laws. 


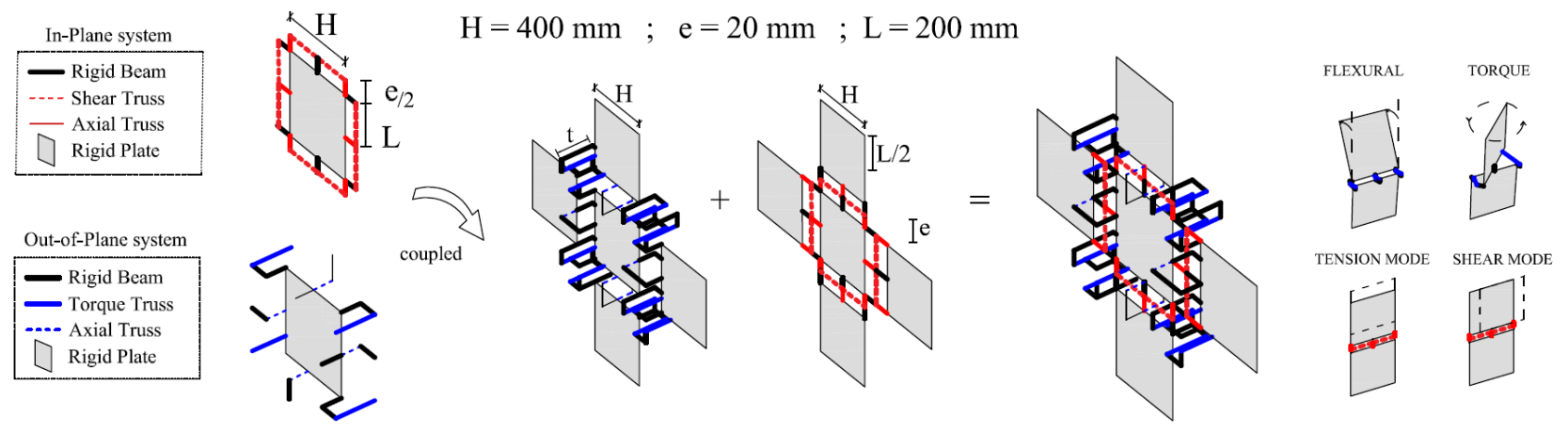

Figure 2. Description of the basic in- and out-of-plane FE truss-beam systems of the discrete macro-unit cell.

\section{Results: Dynamic analysis}

Dynamic analyses have been performed. A set of eight seismic input signals are applied to the benchmark but only the last two (acc07 and acc08) are plotted. An implicit procedure within a Hilber-Hughes-Taylor (HHT) time integration scheme and with a $\alpha$-operator value of -0.05 is assumed for this study [21]. The material damping was defined via the practical approach of the equivalent Rayleigh damping [22]. The Rayleigh parameters were computed by considering a 3\% damping ratio and with a damped range of frequencies of 7-40 Hz.

The comparison between the numerical and experimental data is reached through the time- history of the displacements recorded for the node located at the centre of the gable wall. Figure 3a,b makes clear that none of the numerical curves fit the experimental data. The differences are obvious for the acc07 (see Figure $3 \mathrm{a}$ ) but the latter lack of agreement is especially stressed for the last seismic signal (acc08) wherein the order of magnitude of the experimental peak displacement is two times higher than the numerical ones (Figure 3b).

The use of biased values for the numerical elastic stiffness and strength parameters (average values) hinders a proper fit with the experimental response. Towards a better numerical response, the elastic Young modulus was calibrated through the modal frequencies $\left(E_{x x}=3840 \mathrm{MPa}, E_{y y}=2160 \mathrm{MPa}\right.$ and $\left.\mathrm{G}_{\mathrm{xy}}=1600 \mathrm{MPa}\right)$ and the strength parameters (tensile strength and cohesion) reduced 20\%. The value of damping was kept equal to 3\%. The compressive behaviour seems to have, as expected, a not significant effect and thus the average value was followed. Likewise, the parameters that control the material curves beyond the peak were kept the same, namely the fracture energies, because these refer to typical masonry literature values and no experimental reference is known.

The obtained results are addressed in Figure 3c,d. The comparison is, for the acc07, promising. Figure $3 \mathrm{c}$ states the very good agreement between the calibrated model and the experimental time-history displacements. Also, Figure 4a shows that some cracking occurs but its effect is local and not significant in the overall behaviour. Nevertheless, the response of the DNS model for the acc08 is not so accurate. The authors found that the structure has a moderate damage at the instant $t=28$ seconds, as shown in Figure $4 \mathrm{~b}$. Figure $4 \mathrm{c}$ illustrates that half a second later ( $\mathrm{t}=28.5$ seconds), the out-of-plane failure mode of the gable wall is well active with severe damage 
around the East façade opening and tympanum. Likewise, some in-plane damage is visible for the North façade in which it is clear the tension damage due to the uplift of the pier.
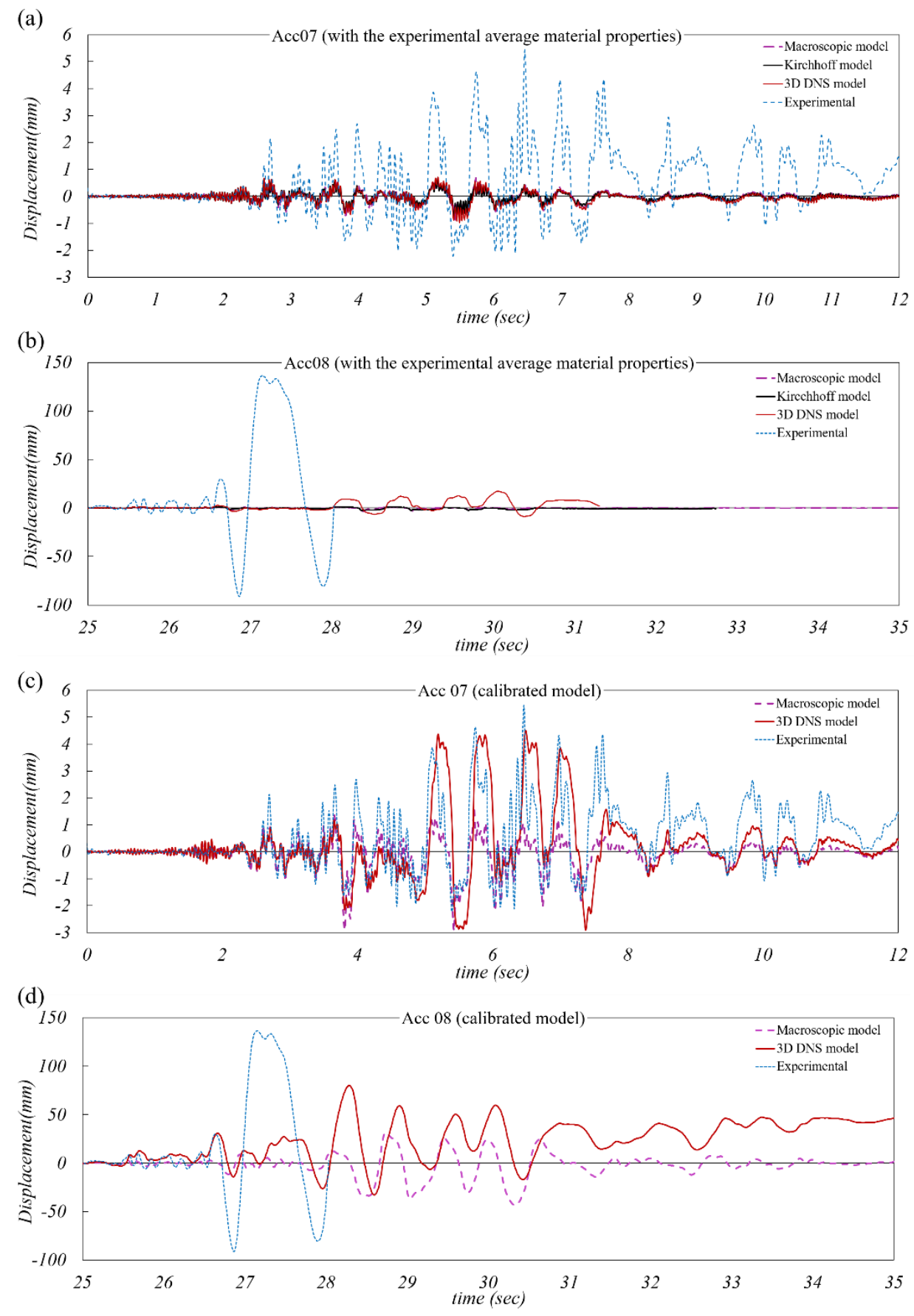

Figure 3. Obtained time-history displacements.

Predict with certainty the collapse is, when using the present framework, questionable. In fact, due to numerical issues, a residual strength of $10 \%$ is guaranteed by the CDP model. Hence, conclusions on the occurrence of the structure collapse and its time instant can be drawn upon the visible damage but the choice lacks a rational sense. Note that residual displacements can be described by the procedure because it derives from the constitutive cyclic behaviour defined by a scalar damage within the CDP model [18]. On the other hand, the macroscopic DIANA model seems to overestimate the structure capacity. The response is, for both acc07 and acc 08 , far for 
being alike with the behaviour reproduced by the present proposed procedure, despite sharing both the same material and mechanical data. The non-consideration of the masonry orthotropy and, more importantly, the disregard of the existent vertical discontinuity are key details. In fact, the latter is paramount once, when present, it decreases significantly the bending and torsional capacities.

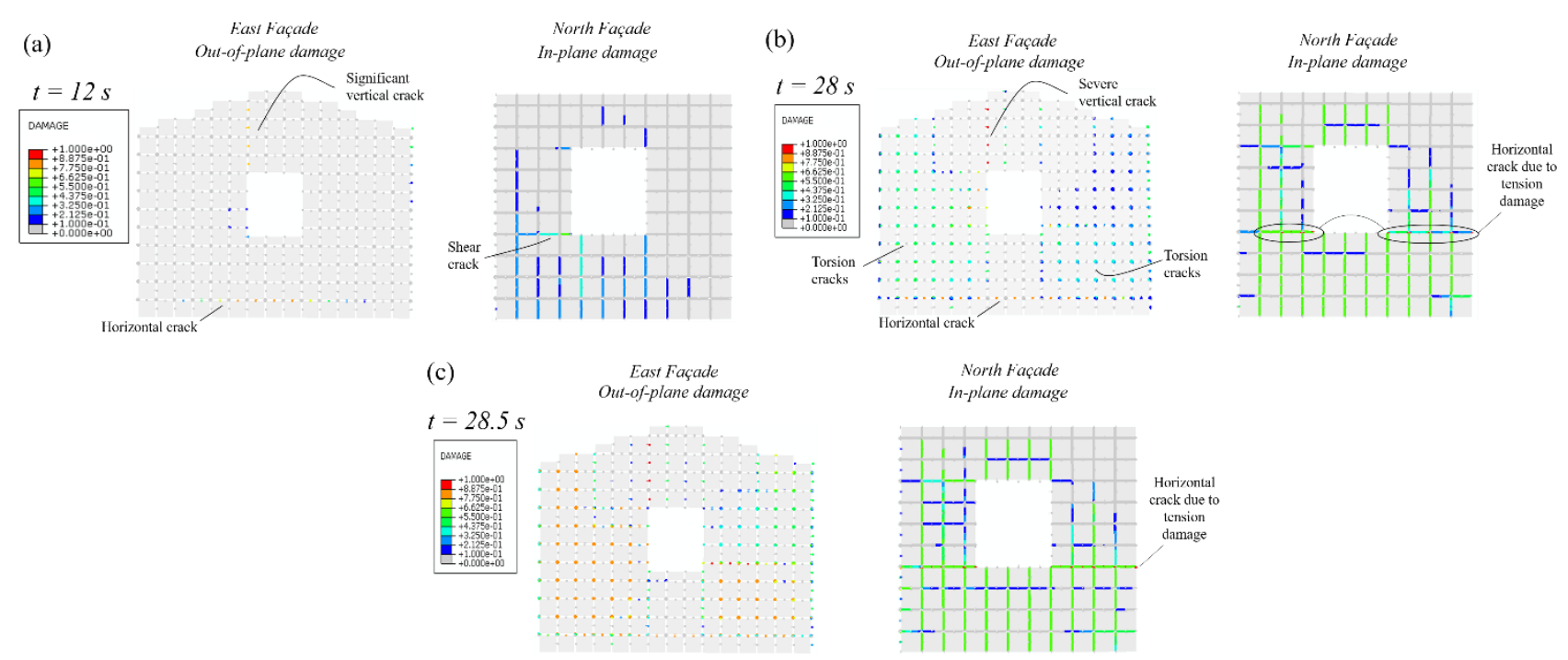

Figure 4. Observed damage for the 3D DNS calibrated model: (a) $t=12$ seconds; (b) $t=28.0$ seconds; and (c) $t=28.5$ seconds.

\section{Conclusions}

A two-step framework has been presented and the results from quasi-static and dynamic analyses reported. Both Kirchhoff and DNS model consider the masonry orthotropy and the full non-linear softening behaviour, but the latter does account it in the presence of the vertical mortar discontinuity in the English bond-masonry thickness and taking the effect of out-of-plane shear stresses. The difference between the models can be clearly noted by the obtained discrepancies for the last accelerogram (Figure 3b). Considering the vertical discontinuity in the English-bond masonry thickness leads to a lower bending capacity and result, therefore, in displacements higher than the Kirchhoff and macroscopic models. The authors do believe that the 3D-DNS model is the more accurate and representative. The initial use of higher strength values for the masonry brickwork justifies the results difference of Figure 3a-b and, likewise, why analogous observations were collected by several other authors on the same brick-house mock-up. A calibrated model with reduced properties was developed and a good agreement was obtained, mainly for the accelerogram seven (Figure 3c). The authors stress that the Kirchhoff model and the macroscopic approach, in which the material is modelled as homogeneous in the thickness direction, may be used with special attention for the masonry study. In cases where discontinuities are present as within the English-bond case, inaccurate solutions are expected to be found.

At last, may be highlighted that, as required, the present approach demands significantly lower computational times than a macroscopic one (around 1000 times lower). 


\section{Acknowledgments}

This work was supported by FCT (Portuguese Foundation for Science and Technology), within ISISE, scholarship SFRH/BD/95086/2013. This work was also partly financed by FEDER funds through the Competitivity Factors Operational Programme - COMPETE and by national funds through FCT - Foundation for Science and Technology within the scope of the project POCI-01-0145-FEDER-007633.

\section{References}

[1] Pande GN, Liang JX, Middleton J. Equivalent elastic moduli for brick masonry. Comput Geotech 1989;8:243-65. doi:10.1016/0266-352X(89)90045-1.

[2] Anthoine A. Derivation of the in-plane elastic characteristics of masonry through homogenization theory. Int $\mathbf{J}$ Solids Struct 1995;32:137-63. doi:10.1016/0020-7683(94)00140-R.

[3] Luciano R, Sacco E. Homogenization technique and damage model for old masonry material. Int J Solids Struct 1997;34:3191-208. doi:10.1016/S0020-7683(96)00167-9.

[4] Mistler M, Anthoine A, Butenweg C. In-plane and out-of-plane homogenisation of masonry. Comput Struct 2007;85:1321-30. doi:10.1016/j.compstruc.2006.08.087.

[5] Zucchini A, Lourenço P. A micro-mechanical model for the homogenisation of masonry. Int J Solids Struct 2002;39:3233-55. doi:10.1016/S0020-7683(02)00230-5.

[6] Milani G, Lourenço P, Tralli A. 3D homogenized limit analysis of masonry buildings under horizontal loads. Eng Struct 2007;29:3134-48. doi:10.1016/j.engstruct.2007.03.003.

[7] Geers MGD, Kouznetsova VG, Brekelmans WAM. Multi-scale computational homogenization: Trends and challenges. J Comput Appl Math 2010;234:2175-82. doi:10.1016/j.cam.2009.08.077.

[8] Milani G, Venturini G. Automatic fragility curve evaluation of masonry churches accounting for partial collapses by means of 3D FE homogenized limit analysis. Comput Struct 2011;89:1628-48. doi:10.1016/j.compstruc.2011.04.014.

[9] Casolo S, Milani G. A simplified homogenization-discrete element model for the non-linear static analysis of masonry walls out-of-plane loaded. Eng Struct 2010;32:2352-66. doi:10.1016/j.engstruct.2010.04.010.

[10] Silva LC, Lourenço PB, Milani G. Nonlinear discrete homogenized model for out-of-plane loaded masonry walls. J Struct Eng (United States) 2017;143. doi:10.1061/(ASCE)ST.1943-541X.0001831.

[11] Silva LC, Lourenço PB, Milani G. Rigid block and spring homogenized model (HRBSM) for masonry subjected to impact and blast loading. Int J Impact Eng 2017;109:14-28. doi:10.1016/j.ijimpeng.2017.05.012.

[12] Lee JS, Pande GN, Middleton J, Kralj B. Numerical modelling of brick masonry panels subject to lateral loadings. Comput Struct 1996;61:735-45. doi:10.1016/0045-7949(95)00361-4.

[13] Taliercio A. Closed-form expressions for the macroscopic in-plane elastic and creep coefficients of brick masonry. Int J Solids Struct 2014;51:2949-63. doi:10.1016/j.ijsolstr.2014.04.019.

[14] Candeias PX, Costa AC, Mendes N, Costa AA, Lourenço PB. Experimental Assessment of the Out-of-Plane Performance of Masonry Buildings Through Shaking Table Tests. Int J Archit Herit 2016:1-28. doi:10.1080/15583058.2016.1238975.

[15] DIANA. User's manual 2017.

[16] Lourenço PB, Rots JG. Multisurface Interface Model for Analysis of Masonry Structures. J Eng Mech 1997;123:660-8. doi:10.1061/(ASCE)0733-9399(1997)123:7(660).

[17] Zijl, Van GPAG. Computational Modelling of Masonry Creep and Shrinkage. Delft University of Technology, 2000.

[18] Abaqus. Finite Element Analysis (Theory manual). Providence: RI: Dassault Systèmes Simulia Corporation; 2006.

[19] Silva LC, Lourenço PB, Milani G. Derivation of the out-of-plane behaviour of masonry through homogenization strategies: micro-scale level. Comput Struct 2018.

[20] Kawai T. New Discrete Structural Models and Generalization of the Method of Limit Analysis. Finite Elem. Nonlinear Mech. P.G. Bergan al. eds, Tapir Publishers; 1977, p. 885-906.

[21] Hilber HM, Hughes TJR, Taylor RL. Improved numerical dissipation for time integration algorithms in structural dynamics. Earthq Eng Struct Dyn 1977;5:283-92. doi:10.1002/eqe.4290050306.

[22] Chopra AK. Dynamics of structures: theory and applications to earthquake engineering. Pearson Prentice Hall; 2017. 